\title{
FEM simulation and experimental determination of the temperature profile of nanoparticles excited by laser radiation
}

\author{
Nuno F. G. Rodrigues ${ }^{\text {a, b , , Carla C. Rosa }}{ }^{a, b}$, João M. P. Coelho cd
}

a Departamento de Física e Astronomia, Faculdade de Ciências, Universidade do Porto, Portugal

b INESC TEC, Porto, Portugal

c Laboratório de Óptica, Lasers e Sistemas, Faculdade de Ciências, Universidade de Lisboa, Lumiar, 1649-038 Lisboa, Portugal

d Instituto de Biofísica e Engenharia Biomédica, Faculdade de Lisboa, Campo Grande, 1749-016 Lisboa, Portugal

\section{Abstract}

Cancer cells can be easily killed when they reach a temperature above 40 degrees. This is known as hyperthermia and the incorporation of nanoparticles (NPs) is helpful to locally rise the temperature. The local heating of NPs could also be used to deliver drugs encapsulated in a specific location inside a body. To achieve the local heating it is necessary to know the temperature profile of the NPs when excited by laser radiation. The COMSOL software was used to simulate the temperature profile of the NPs in an aqueous solution (the cells are mainly composed of water).

An analysis is made regarding the temperature rise for different irradiation parameters, NPs concentration and the corresponding potential of locally heatin cancerous cells without significantly heating adjacent healthy cells.

\section{Results}


Figure 1: Sample consisting of only wate

Figure 2: NPs in a water solutions with a concentration of $0,1 \mathrm{nM}$

In Figures 1, 2 and 3 are shown the temperature evolution after irradiated during 300 s with a CW laser $(980 \mathrm{~nm}, 1 \mathrm{~W})$ and a minimum beam waist of $1.6 \mu \mathrm{m}$, respectively samples of $0.5 \times 1 \mathrm{~cm}$ consisting of only water, a water solution with 0.1 and $1 \mathrm{nM}$. Because of the axial symmetry property used in the COMSOL software, the samples have a real dimension of $1 \times 1 \mathrm{~cm}$ and the simulation of the whole sample is obtained simply by revolving the figure around the $z$ axis. In

Figure 4 is shown the temperature profile along $r \sim-0.5 \mathrm{~mm}$ which represents the center of the sample for a concentration of $0.1 \mathrm{nM}$ and $1 \mathrm{nM}$.

The results reported here are fairly close to those reported by Hsiangkuo Yuan et al. $^{2}$ who reported an increase to $60^{\circ} \mathrm{C}$ for a solution with a concentration of 0.1 $\mathrm{nM}$ and to $80^{\circ} \mathrm{C}$ for $1 \mathrm{nM}$ with a CW laser at $980 \mathrm{~nm}$ and $1.2 \mathrm{~W}$ as an output

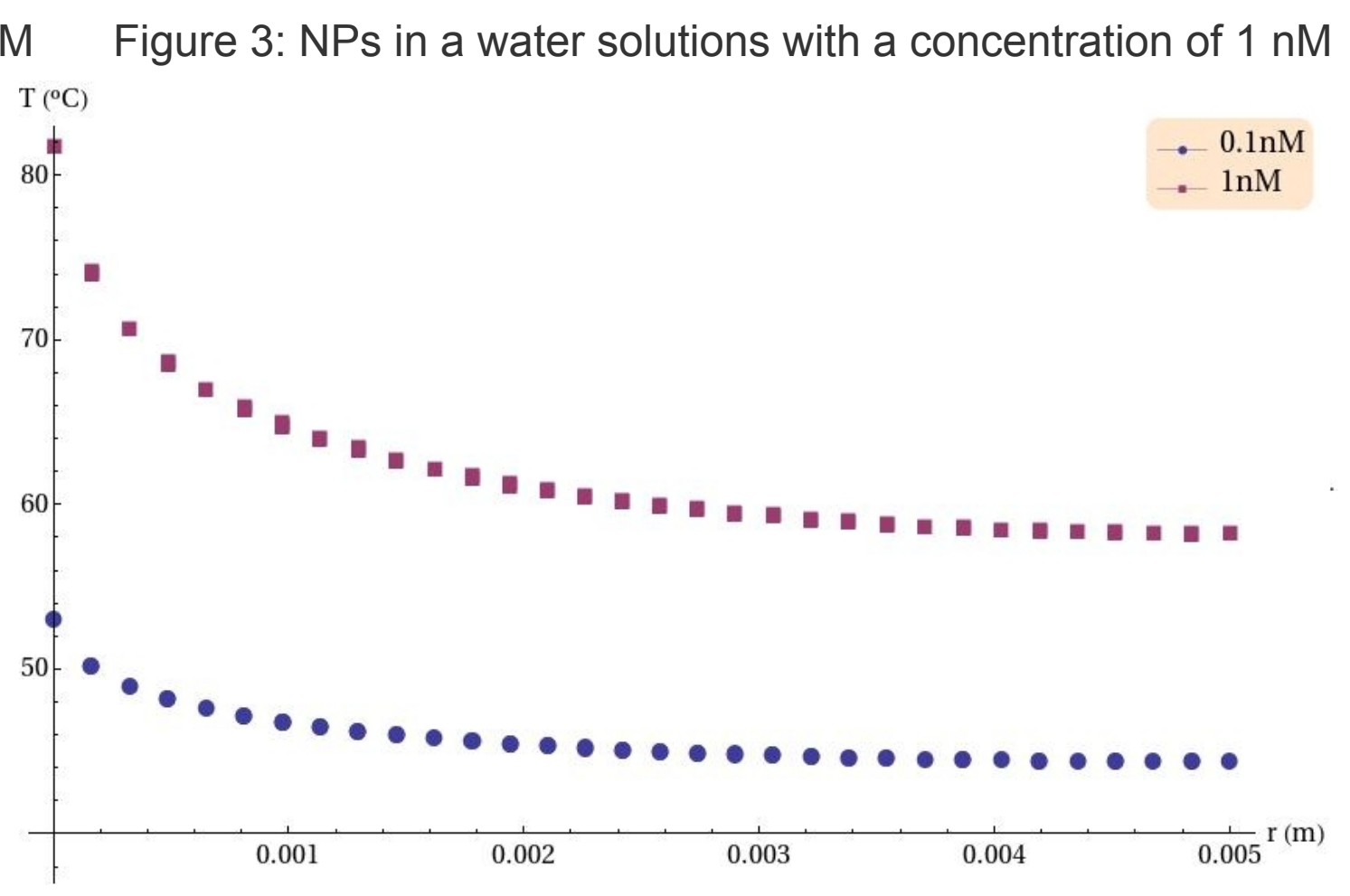
power.

\section{Future Work}

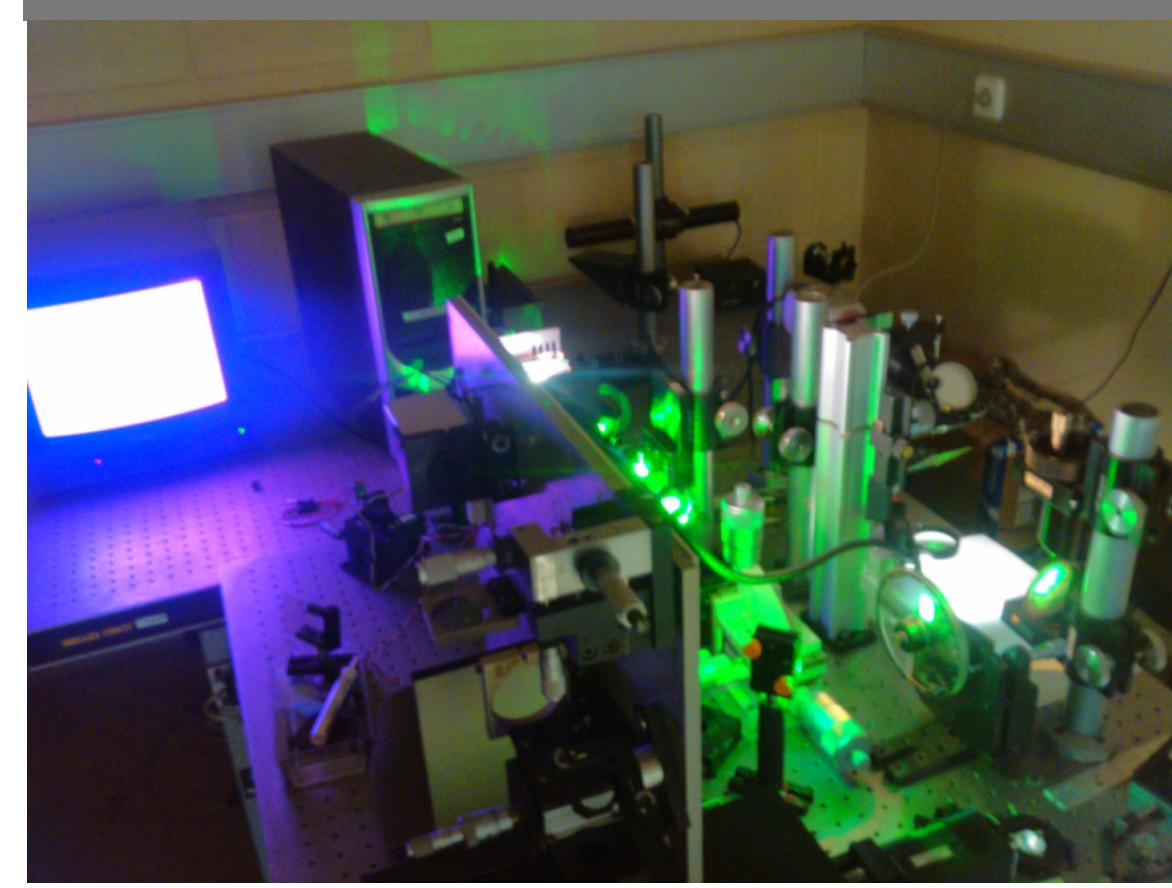

The next step in this work is to validate experimentally the data obtained with the simulations. For this prupose, in Figure 5 is shown one part of the experimental set-up. As reported by Laura M. Maestro et al ${ }^{5}$, we will use a second laser to induce one-photon excitation on quantum dots (1-4 $\mathrm{nm}$ ) incorporated in the samples in order to obtain the spatial variation in real-time and a promising sensitivity of $0.2^{\circ} \mathrm{C}$.

\section{References}

[1] Dewhirst, M. W., Vujaskovic, Z., Jones, E., and Thrall, D., "Re-setting the biologic rationale for thermal therapy" Int. J. Hyperthermia 5, 779-790 (2005).

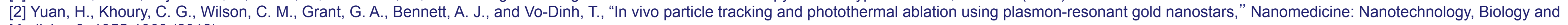
Medicine 8, 1355-1363 (2012).

[3] Niemz, M. H., [Laser-Tissue Interactions Fundamentals and Applications], Springer, Berlin, third ed. (2007).

[4] Kennedy, L. C., Bickford, L. R., Lewinski, N. A., Coughlin, A. J., Hu, Y., and Day, E. S., "A new era for cancer treatment: gold-nanoparticle mediated thermal therapies," Small 7, 169\{183 (2011)

[5] Maestro, L. M., Jacinto, C., Silva, U. R., Vetrone, F., Capobianco, J. A., Jaque, D., and Sole, J. G., "CdTe quantum dots as nanothermometers: Towards highly sensitive thermal imaging," Small 7, 1774-1778 (2011). 